\title{
The extracellular matrix of the lung and its role in edema formation
}

\author{
PAOLO PELOSI ${ }^{1}$, PATRICIA R.M. ROCCO ${ }^{2}$, DANIELA NEGRINI ${ }^{3}$ and ALBERTO PASSI ${ }^{3}$ \\ ${ }^{1}$ Servizio di Anestesia B, Department of Ambient, Health and Safety, University of Insubria, \\ Ospedale di Circolo e Fondazione Macchi, viale Borri 57, 21100 Varese, Italy \\ ${ }^{2}$ Laboratório de Investigação Pulmonar, Instituto de Biofísica Carlos Chagas Filho, Universidade Federal do Rio de Janeiro, \\ Centro de Ciências da Saúde, Ilha do Fundão, 21941-902 Rio de Janeiro, RJ, Brasil \\ ${ }^{3}$ Department of Experimental, Biomedical and Clinical Sciences, University of Insubria, \\ Via HG Dunant 5, 21100 Varese Italy \\ Manuscript received on March 29, 2007; accepted for publication on April 24, 2007; \\ presented by LUCIA MENDONÇA PREVIATO
}

\begin{abstract}
The extracellular matrix is composed of a three-dimensional fiber mesh filled with different macromolecules such as: collagen (mainly type I and III), elastin, glycosaminoglycans, and proteoglycans. In the lung, the extracellular matrix has several functions which provide: 1) mechanical tensile and compressive strength and elasticity, 2) low mechanical tissue compliance contributing to the maintenance of normal interstitial fluid dynamics, 3) low resistive pathway for an effective gas exchange, d) control of cell behavior by the binding of growth factors, chemokines, cytokines and the interaction with cell-surface receptors, and e) tissue repair and remodeling. Fragmentation and disorganization of extracellular matrix components comprises the protective role of the extracellular matrix, leading to interstitial and eventually severe lung edema. Thus, once conditions of increased microvascular filtration are established, matrix remodeling proceeds fairly rapidly due to the activation of proteases. Conversely, a massive matrix deposition of collagen fiber decreases interstitial compliance and therefore makes the tissue safety factor stronger. As a result, changes in lung extracellular matrix significantly affect edema formation and distribution in the lung.
\end{abstract}

Key words: collagen, glycosaminoglycans, proteoglycan, interstitial pressure.

\section{INTRODUCTION}

The Extracellular Matrix (ECM) represents the threedimensional scaffold of the alveolar wall, which is composed of a layer of epithelial and endothelial cells, their basement membrane and a thin layer of interstitial space lying between the capillary endothelium and the alveolar epithelium (West and Mathieu-Costello 1999).

In the segment where the epithelial and endothelial basement membranes are not fused, the interstitium is composed of cells, the fluid phase of the ECM and a macromolecular fibrous component. This fibrous mesh consists mainly of collagen types I and III, which provide

Correspondence to: Prof. Paolo Pelosi

E-mail: ppelosi@hotmail.com tensile strength, elastin conveying elastic recoil (Rocco et al. 2001, 2003), and glycosaminoglycans (GAGs), the major components of the non-fibrillar interstitium compartment (Negrini et al. 2003, Souza-Fernandes et al. 2006). In the lung, the ECM plays several roles which provide: a) mechanical tensile and compressive strength and elasticity; b) low mechanical tissue compliance contributing to the maintenance of normal interstitial fluid dynamics (Miserocchi et al. 1993); c) low resistive pathway for an effective gas exchange, d) control of cell behavior by the binding of growth factors, chemokines, cytokines and the interaction with cell-surface receptors (Johnson et al. 2005), and e) tissue repair and remodeling. Although many functions of ECM are very well described (Roberts et al. 1997, Noble and Jiang 2006) 
the role of ECM components on the maintenance of interstitial fluid volume needs to be better clarified.

In this review, we will discuss the ECM organization and the relationship between ECM and lung edema.

\section{THE EXTRACELLULAR MATRIX ORGANIZATION}

The ECM consists of fibrous proteins (collagen and elastin) and structural or adhesive proteins (fibronectin and laminin) embedded in a hydrated polysaccharide gel containing several glycosaminoglycans.

\section{COLLAGEN}

Collagen fibers constitute the main component of the ECM and are a fibrous protein that consists of three $\alpha$ chains, which form a rope-like triple helix, providing tensile strength to the ECM (Montes 1996). Despite their broad diversity in the connective tissue, types I, II, III (fibrillar) and IV, V, VI (non fibrillar or amorphous) represent the main collagen fibers. Type III collagen fiber is more flexible and susceptible to breakdown, type I collagen is comprised of thicker more cross-linked fibril (Rocco et al. 2001, Santos et al. 2006), whereas type IV collagen fiber is located mainly in basement membrane. Their turnover is a dynamic process, necessary to the maintenance of the normal lung architecture (Rocco et al. 2003). The final collagen accumulation does not depend only on its synthesis, but also, on its degradation (Rocco et al. 2001, 2003). Consequently, the ECM is a dynamic structure, and equilibrium between synthesis and degradation of ECM components is required for the maintenance of its homeostasis (Santos et al. 2006).

\section{ELASTIN}

Elastic fibers represent another constituent of the ECM and comprise three components defined according to their amount of elastin and fibril orientation: 1) oxytalan fiber composed of a bundle of microfibrils, 2) elaunin fibers made up of microfibrils and a small amount of elastin, and 3) fully developed elastic fibers consisting of microfibrils and abundant elastin (Montes 1996). Many types of cells, including condroblasts, myofibroblasts, and smooth muscle cells synthesize these fibers. Due to their mechanical properties, elastic fibers provide recoil tension to restore the parenchyma to its previous configuration after stimulus for inspiration has ceased. In normal alveolar septa, a subepithelial layer of elastic fibers composed mainly of fully developed elastic fibers, confers a great elasticity to the alveolar tissue in normal situations (Mercer and Crapo 1990). Elastosis, as determined by septal inflammation and fiber fragmentation, leads to derangement of the alveolar wall architecture (Negri et al. 2000, Rocco et al. 2003). In response to increased tissue destruction, reactivation of elastin synthesis is observed, resulting in significant changes in the mechanical properties of the lung (Rocco et al. 2001).

\section{GLYCOSAMINOGLYCANS AND PROTEOGLYCANS}

In the connective tissue, proteoglycans (PGs) form a gelatinous and hydrated substance embedding the fibrous proteins. Proteoglycans are constituted of a central protein bound to one or more polysaccharides, denominated glycosaminoglycans (GAGs).

\section{GLYCOSAMINOGLYCANS}

GAGs are long, linear, and heterogeneous polysaccharides, which consist of repeating disaccharide units. There are two main types of GAGs: 1) Non-sulfated GAG (hyaluronic acid) and 2) Sulfated GAGs (heparan sulfate and heparin, chondroitin sulfate, dermatan sulfate, and keratan sulfate). With the exception of hyaluronic acid, GAGs are usually covalently attached to a protein core, forming an overall structure referred to as proteoglycans (Souza-Fernandes et al. 2006).

\section{Non sulfated glycosaminoglycan: hyaluronic acid}

Hyaluronic acid is the most abundant and the largest non-sulfated GAG in the ECM. It is primarily synthesized by mesenchymal cells, being a necessary molecule for the assembly of a connective tissue matrix and an important stabilizing constituent of the loose connective tissue. It also participates in tissue hydration (Tammi et al. 2002), and is involved in several other functions, such as tissue repair (Li et al. 2000), and protection against infections and proteolytic granulocyte enzymes (Cantor et al. 2000).

\section{Sulfated glycosaminoglycans}

These other GAGs are synthesized intracellularly, sulfated, secreted, and usually covalently bound into pro- 
teoglycans. The polyanionic nature of GAGs is the main determinant of the physical properties of PGs molecules, allowing them to resist compressive forces and to simultaneously maintain tissue hydration. They are much smaller than HA, usually only 20 to 200 sugar residues long (Souza-Fernandes et al. 2006).

Within the lung parenchyma, the most abundant sulfated GAG is heparan sulfate, a polysaccharide that is expressed in virtually every cell in the body and comprises $50 \%$ to $90 \%$ of the total endothelial PGs (Whitelock and Iozzo 2005). Although it is initially produced in a cellsurface-bound form, it can also be shed as a soluble GAG. The mechanism of action of heparan sulfate includes a specific and non-covalent interaction with various proteins which affects the topographical destination, halflife, and bioactivity of the protein. Furthermore, heparan sulfate acts on morphogenesis, development, and organogenesis (Whitelock and Iozzo 2005). Heparan sulfate is also involved in a variety of biological processes including cell-matrix interactions and activation of chemokines, enzymes, and growth factors (Whitelock and Iozzo 2005).

Heparin is the most highly modified form of heparan sulfate. This GAG, which can be considered an oversulfated intracellular variant of the heparan sulfate, is commonly used in patients as an anticoagulant drug (Whitelock and Iozzo 2005). Heparin and heparan sulfate are very closely related and may share many structural and functional activities. The lung is a rich native source of heparin. Heparin's abundance may be explained by the fact that the lung is rich in mast cells, which may be heparin's sole original cell. Mast cell heparin resides in secretory granules, where most of the GAG chains are linked to a core protein (serglycin), forming macromolecular PGs much larger than commercial heparin. Very little heparin is incorporated into cell surface PG of epithelial and endothelial cells that are more likely to contain heparan sulfate, which in turn is under-sulfated compared with heparin. Some heparan sulfate chains of vascular endothelium contain short heparin-like sequences. However, most native lung heparin is locked up in mast cells as large PGs. This does not necessarily mean that heparin's physiological action occurs exclusively within cells, because stimulated mast cells secrete heparin outside the cell along with granule-associated mediators, such as histamine, chymase, and tryptase (Ruoss et al. 1991).

\section{PROTEOGLYCANS}

In the lung, the main PGs families may be distinguished based on GAGs composition, molecular weight, and function: chondroitin sulfate-containing PG (CS-PG: Versican), heparan sulfate-containing PGs (HS-PGs: Perlecan and Glypican), chondroitin and heparan sulfatecontaining PGs (CS-HS-PGs: Syndecan), and dermatansulfate-containing PGs (DS-PG: Decorin). They are localized in different areas of the extracellular matrix: versican in the pulmonary interstitium, perlecan in the vascular basement membrane, decorin in the interstitium and in the epithelial basement membrane linked with collagen fibrils, syndecan and glypican in the cell surface (Roberts et al. 1997).

Versican is a large molecule found around lung fibroblasts and blood vessels in regions not occupied by collagen and elastin (Roberts et al. 1997). The precise function of versican is unclear but it is thought to be involved in tissue hydration in mature tissues. It may form aggregates with hyaluronic acid, fibronectin and various collagens, playing an important role in cell to matrix interaction. Versican has been shown to link with smooth muscle cells in the walls of airways and lung vessels, inhibiting cell-matrix adhesion (Iozzo and Murdoch 1996), regulating mesenchymal cells differentiation and, stimulating matrix synthesis, favoring wound healing.

Perlecan is the largest PG in the lung and is a typical component of vascular basement membrane (Yurchenko and Schittny 1990), although it has also been identified within the ECM of some tissues, remote from basement membrane. Certainly its complex core protein provides the potential to interact with numerous proteins. In the basement membranes it provides a filtration barrier interacting with collagen IV limiting flow of macromolecules or cells between two tissue compartments. It also regulates the interaction of the basic fibroblast growth factors with their receptors and modulates tissue metabolism.

Syndecan and glypican are conversely more densely arranged in the cell surface (Zhao et al. 1999). Sindecan's function is commonly associated with its heparan sulfate chains playing a relevant role in wound healing (Tumova et al. 2000). 
Decorin is the smallest dermatan-sulfate-containing PGs. The presence of decorin alters the kinetics of fibril formation and the diameter of the resulting fibril (Roberts et al. 1997) modulating tissue remodeling. Indeed, its name was derived from its surface decoration of collagen fibrils when viewed in the electron microscope.

These data indicate that the function of PGs and GAGs in the lung is not limited to the maintenance of the mechanical and fluid dynamic properties of the parenchyma. These molecules are also important in tissue development and recovery after injury, interacting with inflammatory cells, proteases, and growth factors. Thus, the ECM transmits essential information to pulmonary cells, regulating their proliferation, differentiation, and organization. The structural integrity of the pulmonary interstitium largely depends on the balance between the regulation of synthesis and degradation of ECM components.

\section{EXTRACELLULAR MATRIX METALLOPROTEASIS}

Although many proteases are able to cleave ECM molecules, the family of $\mathrm{Zn}^{++}$matrix metalloproteinases (MMPs) and their inhibitors are likely to be the normal physiologically relevant mediators of ECM degradation (Lanchou et al. 2003, Elkington and Friedland 2006, Greenlee et al. 2007). They can degrade many proteins including collagens, fibronectin, laminin, proteoglycans, entactins, and elastin. In particular, they are very important in: a) the breakdown of ECM and basement membrane, b) tissue remodeling and angiogenesis, and c) the restoration of functional connective tissue in the woundhealing process.

Gelatinases (MMP-2 and MMP-9) are the subgroup of MMPs most extensively studied in human interstitial lung diseases and in experimental models of lung fibrosis, probably due to the facility and great sensitivity of revealing gelatinolytic activity through gelatin zymograms. Both gelatinases contain fibronectin type II-like repeats within their catalytic domain, resulting in a higher binding affinity to gelatin and elastin. The MMP-2 is produced by fibroblasts, endothelial and epithelial cells, and macrophages. MMP-2 (gelatinase A) is known to be effective primarily against type IV collagen and other basement-membrane components although a weak ability to degrade stromal collagens has been also reported.
On the contrary MMP-9 (gelatinase B) is not produced by resident cells, but under various forms of stimulation bronchial epithelial cells, ciliar cells, alveolar type II cells, fibroblasts, smooth muscle cells, and endothelial cells may produce MMP-9. Alveolar type I, neuroendocrine, and goblet cells have not yet been shown to produce MMP-9. Leukocytes in the lung can also be a source of MMP-9. Macrophages, eosinophils, mast cells, lymphocytes, and dendritic cells all can produce MMP-9.

Because MMPs may cause significant host damage, their proteolytic activity is tightly regulated. Thus, MMPs are rarely stored, but require gene transcription before secretion, with the exception of neutrophil MMP8 and -9 . In fact, these are either secreted as pro-enzymes that require proteolytic cleavage or are activated intracellularly by pro-protein convertases such as furin. Specific inhibitors of MMPs - the tissue inhibitors of metalloproteinases (TIMPs) - which bind MMPs in a 1:1 manner are secreted to prevent enzymatic activity; as a result the balance between MMPs and TIMPs determines matrix turnover, where either an excess of MMPs or a deficit of TIMPs may result in excess ECM degradation (Elkington and Friedland 2006).

The majority of MMPs are not expressed in normal healthy tissues, but are expressed in diseased tissues, that are inflamed or undergoing repair and remodeling (Lanchou et al. 2003). MMP expression may be upregulated by exogenous stimuli, cytokines, and cellcell contact. Conversely, cytokines such as interferon (IFN)- $\gamma$ and interleukins (IL)-4 and -10 may down regulate MMP expression. Both inflammatory and stromal cells can express MMPs, although the profile is both cell and stimulus specific.

\section{THE EXTRACELLULAR MATRIX AND THE BASAL MEMBRANE}

The basal lamina of pulmonary cells is extremely complex and it is composed of different molecules like laminin, nidogen, and perlecan (Fig. 1) (Furuyama and Mochitate 2000).

1) Laminin is a $100 \mathrm{~nm}$ long sword-shaped trimmer which self-assembles into a feltlike sheet with the help of its beta/gamma arms (Jones et al. 2005). Laminins are important in linking the cells to their 
basement membranes. The 'sword' tips can bind cell receptors, and the crosspieces allow laminin to bind to other laminin molecules. Other sites for nidogen and perlecan binding are also present in the molecule;

2) Nidogen, also known as entactin, is a dumbbell shaped $150 \mathrm{kDa}$ sulfated glycoprotein, with three domains. Nidogen connects laminin to both the collagen layers and perlecan in the basal lamina;

3) Perlecan, which has a $400 \mathrm{kDa}$ core protein with three heparan sulfate chains attached, is the predominant proteoglycan in the basal lamina. It binds to collagen, laminin, nidogen, and other perlecan molecules (Nguyen et al. 2002).

On one side of the cell membrane, the basal lamina is linked to the cell by means of integrins (Tschumperlin et al. 2004, Ingber 2006,), while on the other side it is liked to the ECM through links to collagen type IV. Integrins are adhesive membrane receptors that exist as heterodimers. They exhibit a "Velcro" effect: i.e. they have strength in numbers, but are individually easy to disrupt. They require $\mathrm{Ca}^{++}$or $\mathrm{Mg}^{++}$to bind, and their job is to link the ECM to the cytoskeleton. Fibronectin reinforces the connections between the basal lamina with both the cell membrane and the other ECM components. It is likely that type IV collagen is chiefly responsible for the great tensile strength of the ECM and that the other molecules play important roles in consolidating the structure of the ECM and its connections with overlying cells.

\section{PULMONARY INTERSTITIAL FLUID DYNAMICS}

The interstitial compartment of the lung is kept at a subatmospheric pressure in physiological conditions, with a low amount of extravascular water. In the lung, a relatively "dry" interstitial space allows a minimum thickness of the air-blood barrier to optimize gas diffusion. A rise in extravascular lung water may occur because of an increase in the pressure gradient across the microvascular barrier and/or by an increase in perm-porosity of the endothelial barrier.

The maintenance of the steady state interstitial fluid turnover results from the balance between several factors, such as: 1) the transendothelial fluid and solutes filtration, 2) the convective outflows into the lymphatic system, and 3) the mechanical and hydrophilic properties of the solid elements of the ECM. The hydraulic pressure of the free liquid phase of the pulmonary interstitium $\left(P_{i}\right)$ reflects the dynamic situation that results from the complex interaction between the factors stated above representing a key variable to understand the mechanisms which control lung fluid balance (Miserocchi et al. 1990, 1997, Negrini et al. 2003). The endexpiratory $P_{i}$ is significantly lower than intra-pleural $\left(P_{l i q}\right)$ and extra-pleural $\left(P_{e p l}\right)$ liquid pressure, indicating that the lung parenchyma is relatively "dehydrated" compared to the other two tissue compartments (Fig. 2). The $P_{i}$ distribution is not uniform within the lung parenchyma, decreasing by $\sim 0.7 \mathrm{cmH}_{2} \mathrm{O} / \mathrm{cm}$ of lung height. The gravity - dependent $P_{i}$ distribution reflects: a) the uneven mechanical stress developing in lung tissue at various lung heights, b) the inhomogeneous perfusion of the lung parenchyma, in analogy with that found in the pleural space, and c) the greater drainage of interstitial fluid into the lymphatic system in the lower regions. During inspiration, sustained by lowered pleural surface pressure, both $P_{l i q}$ and $P_{i}$ become more subatmospheric (Miserocchi et al. 1990, Miserocchi and Negrini 1997, Negrini et al. 2003).

The fluid bulk flow $\left(J_{v}\right)$ between the pulmonary capillaries $(c)$ and the surrounding interstitium $(i)$ is described by the well-known Starling law:

$$
J_{v}=L_{p} \cdot S \cdot\left[\left(P_{c}-P_{i}\right)-\sigma\left(\pi_{c}-\pi_{i}\right)\right]
$$

where $P$ e $\pi$ are the hydraulic and colloidosmotic pressures in the two compartments, $L_{p}$ is the hydraulic filtration coefficient of the pulmonary capillary endothelial layer, $S$ is the exchange surface area and $\sigma$ is the reflection coefficient of the endothelium for total proteins, a correction factor accounting for the protein to endothelial pore radii ratio. The factor in the square parenthesis gives the net pressure gradient across the membrane, $\Delta P_{\text {net }}$.

\section{THE EXTRACELLULAR MATRIX AND LUNG EDEMA}

Figure 3 shows examples of hydraulic $(P)$ and colloidosmotic $(\pi)$ pressures from the pulmonary capillaries $(c)$ and surrounding interstitial space $(i)$ under normal condition, mild or severe interstitial edema. While $P_{i}$ is 


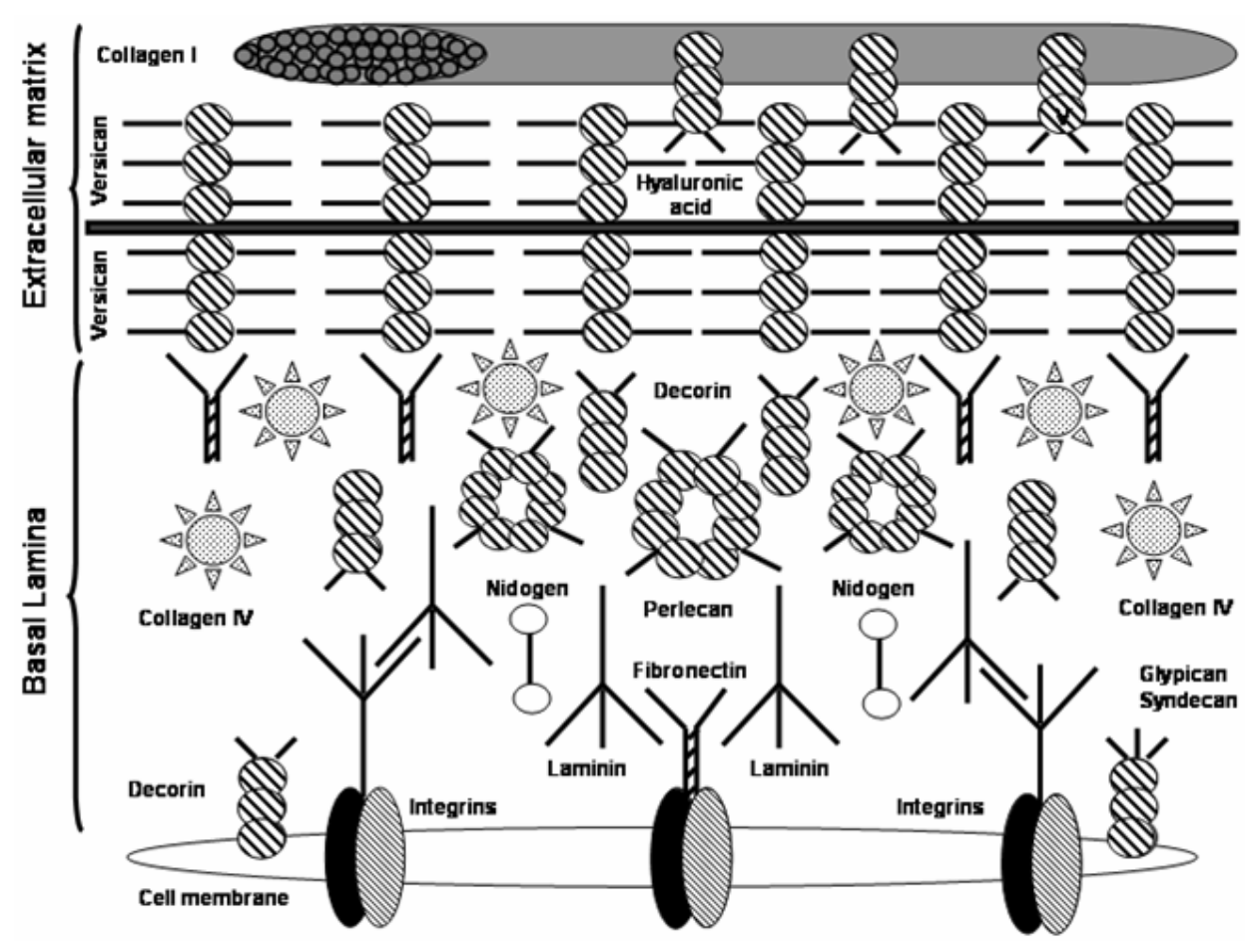

Fig. 1 - Links among the cell membrane, the basal lamina, and the extracellular matrix.

very negative in normal lungs, ensuring the maintenance of a net fluid filtration into the interstitial space, the early phase of interstitial edema is associated to an increase in $P_{i}$ with no significant change in interstitial fluid volume. This phenomenon is caused by the low tissue compliance, provided by the tight structure of the fibrous matrix, and represents an important "tissue safety factor" to counteract further progression of pulmonary edema. With the worsening of the edema, $P_{i}$ drops back to zero and subsequently remains unchanged despite a marked increase in the wet-to-dry weight ratio of the lung. The worsening of edema occurs because of an increasingly high filtration rate, in spite of a progressive augment in $P_{i}$ and thus a reduced $\Delta P_{n e t}$. Hence, at least two factors interact to determine the development of pulmonary edema: 1) the loss of the tissue safety factor, which reflects in an increase of tissue compliance and 2) a rise in microvascular permeability (Passi et al. 1998).

\section{EFFECTS OF HYDRAULIC AND LESIONAL EDEMA ON ECM COMPONENTS}

Interstitial lung edema led to some degree of disorganization of the extracellular matrix, despite its strong me- chanical resistance, particularly at the expense of proteoglycans (Negrini et al. 2003). These molecules are responsible for the structural integrity of pulmonary interstitium as they control fluid dynamics through their influence on microvascular permeability and tissue compliance. They also are involved in cell-cell and cellmatrix interactions and in the cytokine network since they regulate the traffic of the molecules within the interstitial space and promote interactions (Roberts et al. 1997). To better understand the relationship between pulmonary interstitial pressure and the functional state of the matrix, hydraulic and lesional edema were developed in anesthetized rabbits by intravenous injection of saline solution $\left(0.5 \mathrm{ml} \cdot \mathrm{min}^{-1} \cdot \mathrm{kg}^{-1}\right)$ (Miserocchi et al. $1993)$ and a single bolus of pancreatic elastase $(200 \mu \mathrm{g}$, 7 IU) (Negrini et al. 1998), respectively.

In hydraulic edema the biochemical analysis of tissue structure reveals an initial fragmentation of chondroitin sulfate proteoglycan due to mechanical stress and/or proteolysis. On the other hand, in lesional edema, there is a partial fragmentation of heparan sulfate proteoglycan because of enzymatic activity. The fragmentation of proteoglycans is probably induced by increased ex- 


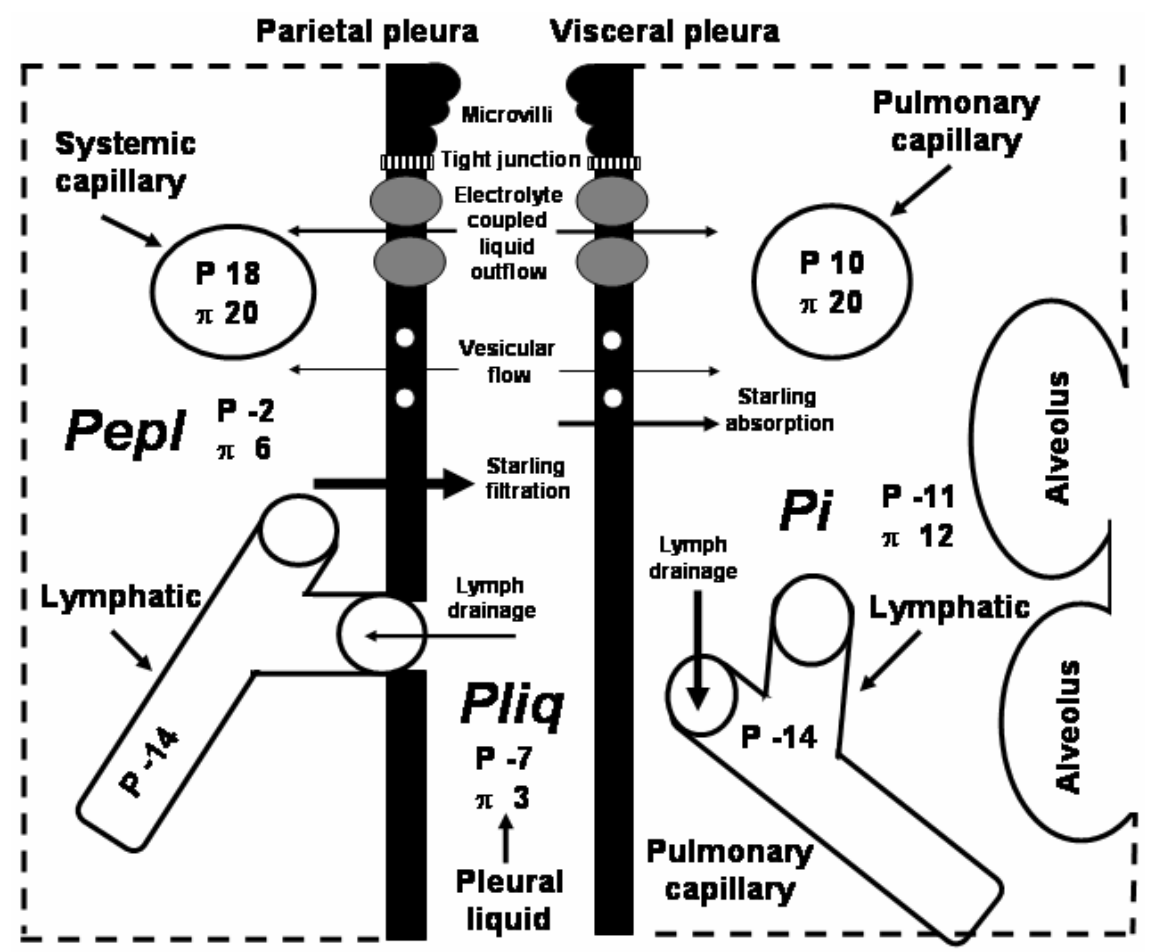

Fig. 2 - Schematic representation of transpleural liquid flows (arrows) under physiological conditions. Mesothelial cells and adjoining interstitium, with embedded capillaries and lymphatics are shown. At the top, the mesothelial cell depicts the cell mechanisms involved in pleural liquid turnover [microvilli, vesicles, electrolyte transporters (grey circles)]. Arrow size is proportional to the corresponding flow magnitude. Hydraulic $(P)$ and colloidosmotic $(\pi)$ pressures $\left(\mathrm{cmH}_{2} \mathrm{O}\right)$ are involved in the Starling balance. Pepl (extrapleural interstitial pressure), Pliq (intrapleural pressure) and Pi (lung interstitial pressure).

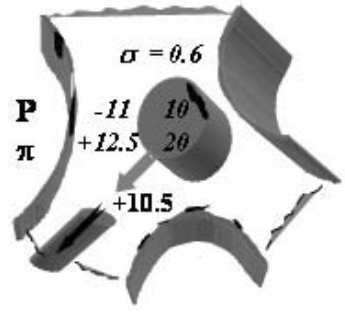

Normal

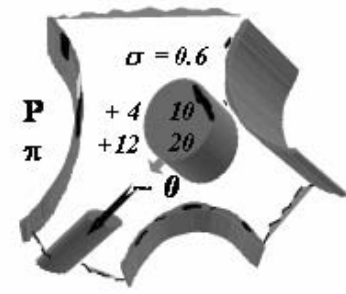

Mild edema

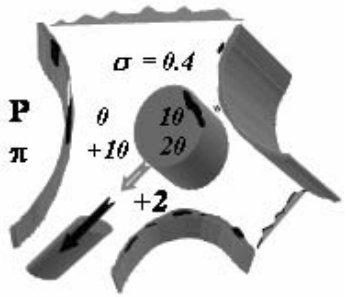

Severe edema

Fig. 3 - Hydraulic $(P)$ and colloidosmotic $(\pi)$ pressures of the microvasculature (cap) and surrounding interstitial space (int) under normal condition, during mild, and severe interstitial edema. Grey arrow represents transendothelial flow while black arrow represents trans-lymphatic flow. Hydraulic $(P)$ and colloidosmotic $(\pi)$ pressures are shown as $\mathrm{cmH}_{2} \mathrm{O}$.

travascular water yielding tissue stress and weakness of PGs non-covalent bands with other matrix molecules or tissue metalloproteinases activation (Passi et al. 1999).
Therefore, the fragmentation of chondroitin sulfate proteoglycan yielded a marked increase in tissue compliance and a loss in tissue safety factor, while hep- 
aran sulfate proteoglycan lesion led to an augment in microvascular permeability (Negrini et al. 1998). Early in the course of hydraulic edema there was an increase in MMP-2, while in lesional edema both MMP-2 and MMP-9 were augmented (Passi et al. 1998).

Contrary to hydraulic edema, hypoxic pulmonary edema led to fragmentation of intermediate molecular weight heparin-sulfate PGs, such as perlecan of the basement membrane (Miserocchi et al. 2001b).

Recent data also suggest that the integrity of the heparan-sulfate proteoglycan components of the pulmonary ECM is required to maintain the three-dimensional architecture of the matrix itself, which in turn, ensures its mechanical response to increased fluid filtration $(\mathrm{Ne}-$ grini et al. 2006).

In an experimental model of fibrosis there was a marked reduction in the absolute volume of edema, in parallel with a reduction in lung volume, suggesting that fibrosis deeply affects the distribution of edema in the lung (Zwinkler et al. 1994).

\section{EXTRACELLULAR MATRIX AND CELL PLASMA MEMBRANE}

The response of epithelial cells to basement membrane deformation is affected by the extracellular matrix, plasma membrane, and cell cytoskeleton. Proteins that link the extracellular matrix with stress bearing cytoskeletal biopolymers play a pivotal role in mechanosensing and transduction (Geiger et al. 2001). They are assembled in so-called focal adhesion sites, plaques, or complexes. Focal adhesions are highly plastic structures and remodel in a force-dependent manner (Coppolino and Dedhar 2000). This allows adherent cells to probe the regional impedance of the surrounding scaffolding and, in turn, provides cues for directional control of locomotion and cell shape (Geiger et al. 2001). The most extensively studied adhesion receptors involved in mechanotransduction are the integrins. After ligandinduced activation, integrins transduce matrix-dependent intracellular biochemical signals. Other adhesion molecules such as cadherins are also increasingly recognized as playing important roles in mechanotransduction and as molecular targets of deformation induced impairments of the epithelial and endothelial barrier function (Cavanaugh et al. 2001).
The relationship between the ECM and plasma membrane has important implications in preventing lung injury. Cells experience plasma membrane stress failure when the matrix to which they adhere undergoes large deformations (Vlahakis and Hubmayr 2005). There are some adaptive responses of the lipid surface to deforming stress in alveolar epithelial cells:

1) the cell might unfold plasma membrane, thus preventing any increase in plasma membrane tension,

2) once unfolded, the plasma membrane stretches,

3) if these responses are overwhelmed, the plasma membrane might either undergo stress failure or further adapt its stress-bearing elements to prevent plasma membrane breaks (Fig. 5) (McNeil and Steinhardt 1997, Akinlaja and Sachs 1998, Liu et al. 1999, Tschumperlin et al. 2000).

Lipid trafficking to the cell surface is another adaptive mechanism in alveolar epithelial cells (Vlahakis et al. 2001) (Fig. 5). Several observations on normal and injured lungs raise interest in the molecule and pathway specificity of deformation triggered vesicular trafficking. When lungs suffer relatively mild forms of interstitial pulmonary edema, the lipid microdomains of lung cell surface membranes undergo a substantial reorganization (Palestini et al. 2003). The functional consequence of membrane remodeling, which is almost certainly accompanied by changes in surface protein expression, remains to be explored. In vitro, such changes are associated with changes in cell phenotype and by inference, changes in the cells susceptibility to mechanical injury. In endothelial cells, fibroblasts, and some epithelial cells, sphingolipids, cholesterol, and glycosylphosphatidylinisotolanchored proteins appear to have a preferential association with 50- to 100-nm pits called caveolae (Razani et al. 2002) (Fig. 5). These structures play an important role in endocytosis processes and can be identified in type I alveolar epithelium cells (Gil 1983, Kasper et al. 1998). Caveolae are plasma membrane invaginations that may unfold when laterally stressed, and may be important not only for the mechanotransduction of deformation-induced lipid trafficking, but also central for the maintenance of sublytic membrane tension.

The biochemical and biophysical changes in plasma membranes were also related to the changes in phys- 


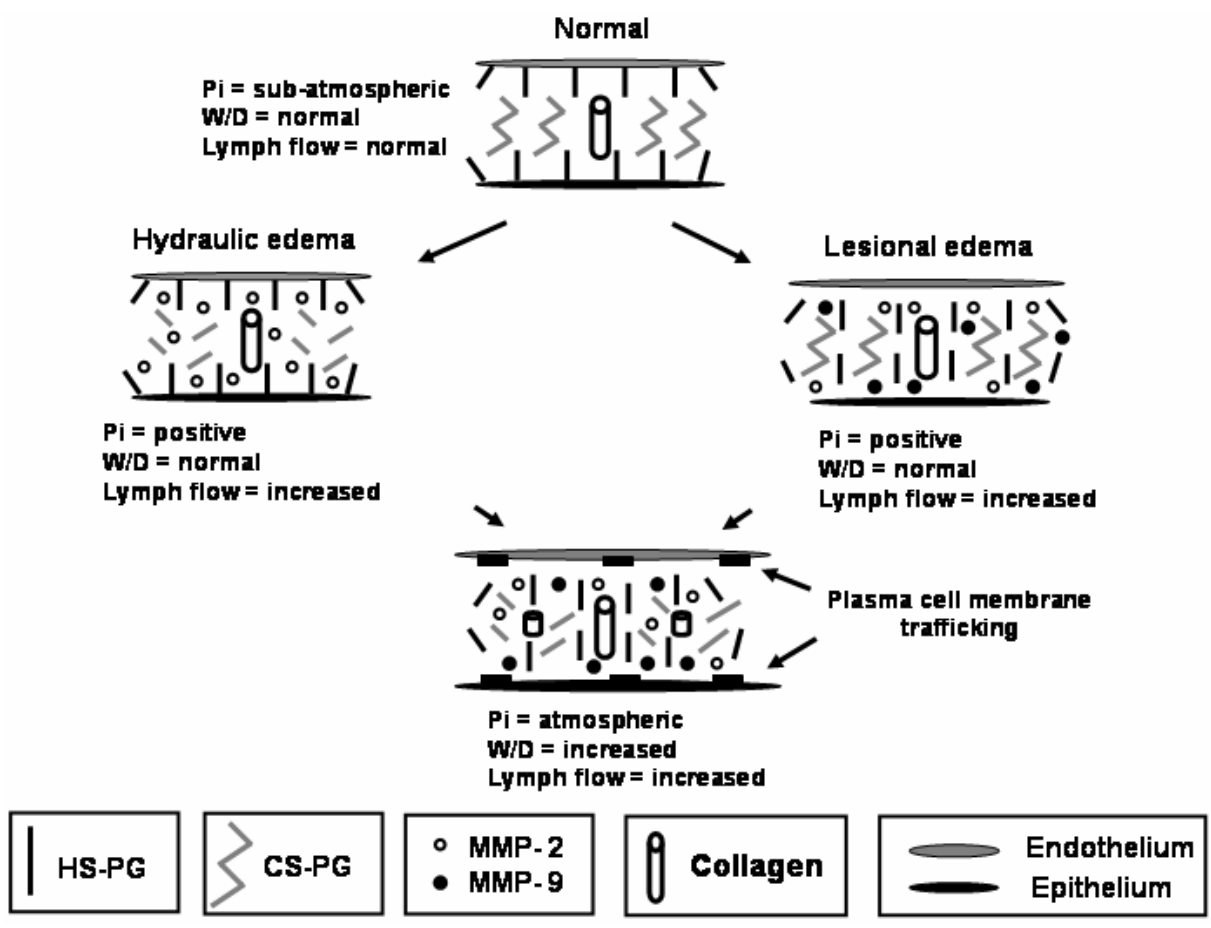

Fig. 4 - Changes in extracellular matrix during hydraulic and lesional edemas. Pi: interstitial pressure, W/D: wet-to-dry weight ratio, HS: Heparan sulfate, PG: Proteoglycan, CS: Chondroitin sulfate. MMP: Matrix Metalloproteasis. During hydraulic edema the prevalent lesion is the fragmentation of the CS, whilst in the lesional edema HS is damaged.

ical stimuli on endothelial cell surface. The increase in tissue forces at interstitial level is a consequence of interstitial fluid accumulation, particularly in the air-blood barrier as demonstrated by the increased thickness of the extracellular matrix. Interstitial edema causes a raise in interstitial fluid pressure from the physiological value of approximately $-10 \mathrm{cmH}_{2} \mathrm{O}$ up to $\sim 5 \mathrm{cmH}_{2} \mathrm{O}$ (Miserocchi et al. 1993, 2001a). As capillary pressure remains essentially unchanged at $\sim 10 \mathrm{cmH}_{2} \mathrm{O}$ in mild interstitial edema (Negrini 1995), the above condition should cause a substantial alteration in the transmural pressure. In fact, in physiological conditions, the transmural pressure is relatively high, averaging $20 \mathrm{cmH}_{2} \mathrm{O}$, with the subatmospheric interstitial pressure pulling the basal side of the cell. Conversely, in edema the transmural pressure gradient is reduced to $5 \mathrm{cmH}_{2} \mathrm{O}$, and the positive interstitial pressure pushes the basal side of the cell. Furthermore, parenchymal forces exerted at focal points where cellmatrix attachments occur are expected to increase as a consequence of swelling of the extracellular matrix.
Daffara and colleagues hypothesize a specific "sensing" function by lung cells resulting from a perturbation in cell-matrix interaction (Daffara et al. 2004). In this context, the cell-matrix interaction may differ according to the type of edema since differences were found in the sequential degradation of PGs family and in the interaction properties of PGs to some matrix components (Miserocchi et al. 2001a). Based on these considerations, Botto and coworkers described a differential response of lung endothelial cells to hydraulic and hypoxic pulmonary edema, inducing a specific cascade of cellular events from signaling-transduction to cellular functional attitude aimed at tissue repair (Botto et al. 2006).

\section{CONCLUSIONS}

ECM components such as the chondroitin sulfate (versican) and the heparan sulfate (perlecan) proteoglycans play a major role in the maintenance of tissue fluid homeostasis providing: a) a highly restrictive perivas- 

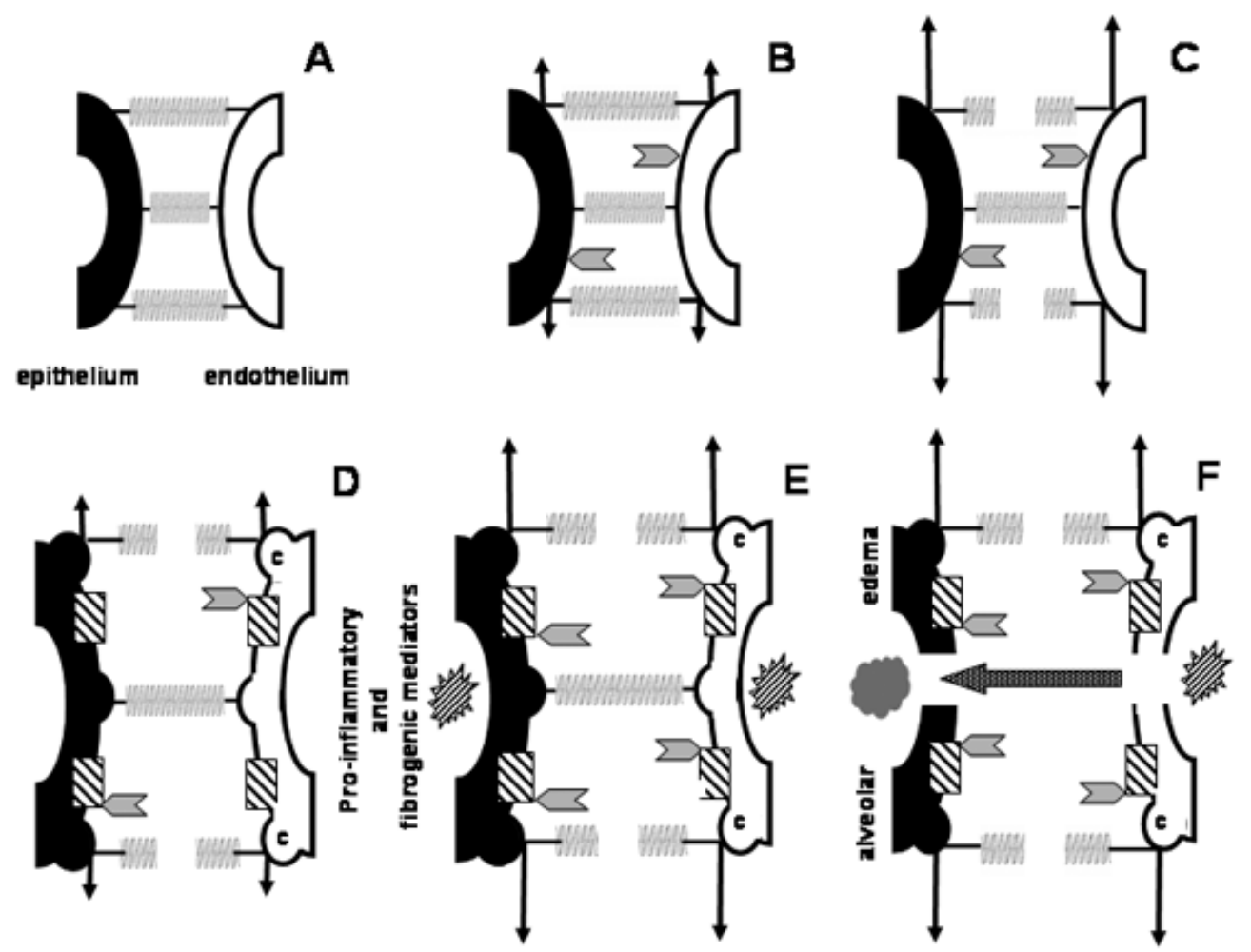

Fig. 5 - Extracellular matrix (ECM) and cell response to increased lung interstitial pressure. Springs represent ECM components. Arrowheads: the intensity of interstitial pressure. Arrows: the intensity of stress on endothelium and epithelium. A: Normal pressure in the interstitium with no cell stress or ECM lesion. Panel B: Increased pressure in the interstitium, with limited cell stress since the ECM is intact. Panel C: During interstitial pressure increase, some components of ECM are ruptured, plasma membrane unfolded and stretched. Panel D: Adaptative cell response: the translocation of lipids from intracellular stores to the plasma membrane (dashed square). Note the presence of caveolae (c) in endothelial and epithelial cells. Panel E: Even though cells sensed the stress early, with further increase in interstitial pressure, proinflammatory and fibrogenic mediators were released. Panel F: Maintenance of increased stress associated with the effects of pro-inflammatory and fibrogenic mediators contribute to the fragmentation of extracellular matrix components and epithelial and endothelial cell rupture resulting in edema.

cular and interstitial sieve in relation to plasma proteins, thus modulating both interstitial protein concentration and trans-endothelial fluid filtration; b) a mechanical support to lymphatic vessels sustaining and modulating their draining function, and c) a rigid three dimension low compliant scaffold opposing fluid accumulation into interstitial space. Fragmentation of proteoglycans induced by different stimuli such as: fluid overload, exposure to proteolytic or inflammatory agents, hypoxic or hyperoxic gas mixtures, or increased tissue strain/stress, result in a progressive loosening of proteoglycans intermolecular connections with other ECM components. The loss of the proteoglycans regulatory functions compromises the protective role of the ECM, leading to interstitial and eventually severe lung edema. Thus, once conditions of increased microvascular filtration are established, matrix remodeling proceeds fairly rapidly due to the activation of proteases. Interestingly enough in experimentally induced fibrosis a massive matrix deposition would be expected to decrease interstitial compliance and therefore make the tissue safety factor stronger. This possible defense against alveolar flooding does not seem to operate, so far. However, it seems that the extensive matrix remodeling led to a decreased hydraulic resistance of 
both the endothelial and the epithelial barrier and possibly of the interstitial matrix.

\section{ACKNOWLEDGMENTS}

We would like to express our gratitude to Mr. Andre Benedito da Silva, and Mrs. Jaqueline Lima do Nascimento for their skillful technical assistance. Supported by: Programa de Apoio a Núcleos de Excelência - Fundação Carlos Chagas Filho de Amparo à Pesquisa no Estado do Rio de Janeiro (PRONEX-FAPERJ), Conselho Nacional de Desenvolvimento Científico e Tecnológico (CNPq), Fundação Carlos Chagas Filho de Amparo à Pesquisa no Estado do Rio de Janeiro State (FAPERJ).

\section{RESUMO}

A matriz extracelular é um aglomerado tridimensional de macromoléculas composta por: fibras colágenas (principalmente, tipos I e III), elastina, glicosaminoglicanos e proteoglicanos. No pulmão, a matriz extracelular tem várias funções, tais como: 1) promover estresse tensil e elasticidade tecidual, 2) contribuir para a manutenção da dinâmica de fluidos no interstício, 3) propiciar efetiva troca gasosa, 4) controlar a função celular através de sua ligação com fatores de crescimento, quimiocinas, citocinas e interação com receptores de superfície, e 5) remodelamento e reparo tecidual. A fragmentação e a desorganização da matriz extracelular pode acarretar edema intersticial e, eventualmente, edema alveolar grave. Logo, quando há aumento da filtração microvascular ocorre rápido remodelamento da matriz por ativação de proteases. Destarte, a deposição de fibras colágenas reduz a complacência intersticial limitando o edema. Em conclusão, modificações na matriz extracelular podem afetar a formação e distribuição do edema no pulmão.

Palavras-chave: colágeno, glicosaminoglicanos, proteoglicanos, pressão intersticial.

\section{REFERENCES}

AKInlaja J AND SACHS F. 1998. The breakdown of cell membranes by electrical and mechanical stress. Biophys J 75: 247-254.

Botto L, Beretta E, DafFara R, Miserocchi G AND PALESTINI P. 2006. Biochemical and morphological changes in endothelial cells in response to hypoxic interstitial edema. Respir Res 7: 7.
Cantor JO, Shteyngart B, Cerreta JM, Liu M, ARMAND G AND TURINO GM. 2000. The effect of hyaluronan on elastic fiber injury in vitro and elastaseinduced airspace enlargement in vivo. Proc Soc Exp Biol Med 225: 65-71.

CAVAnaugh JR KJ, Oswari J AND Margulies SS. 2001. Role of stretch on tight junction structure in alveolar epithelial cells. Am J Respir Cell Mol Biol 25: 584-591.

Coppolino MG AND Dedhar S. 2000. Bi-directional signal transduction by integrin receptors. Int J Biochem Cell Biol 32: 171-188.

DafFara R, Botto L, Beretta E, Conforti E, Faini A, Palestini P and Miserocchi G. 2004. Endothelial cells as early sensors of pulmonary interstitial edema. J Appl Physiol 97: 1575-1583.

ElKington PT AND FRIEDLAND JS. 2006. Matrix metalloproteinases in destructive pulmonary pathology. Thorax 61: 259-266.

Furuyama A And Mochitate K. 2000. Assembly of the exogenous extracellular matrix during basement membrane formation by alveolar epithelial cells in vitro. J Cell Sci 113: 859-868.

Geiger B, Bershadsky A, Pankov R And Yamada KM. 2001. Transmembrane crosstalk between extracellular matrix-cytoskeleton crosstalk. Nat Rev Mol Cell Biol 2: 793-805.

GIL J. 1983. Number and distribution of plasmalemmal vesicles in the lung. Fed Proc 42: 2414-2418.

GreenleE KJ, Werb Z And Kheradmand F. 2007. Matrix metalloproteinases in lung: multiple, multifarious, and multifaceted. Physiol Rev 87: 69-98.

INGBER DE. 2006. Cellular mechanotransduction: putting all the pieces together again. FASEB J 20: 811-827.

IOzzo RV AND MURDOCH AD. 1996. Proteoglycans of the extracellular environment. Clues from the gene and protein side offer novel perspective in molecular diversity and function. FASEB J 10: 598-614.

JoHnson Z, Proudfoot A AND HANDEL T. 2005. Interaction of chemokines and glycosaminoglycans: A new twist in the regulation of chemokine function with opportunities for therapeutic interventions. Cytokine Growth Factor Rev 16: 625-636.

JONES JC ET AL. 2005. Laminin-6 assembles into multimolecular fibrillar complexes with perlecan and participates in mechanical-signal transduction via a dystroglycan-dependent, integrin-independent mechanism. J Cell Sci 118: 2557-2566. 
Kasper M, Reimann T, Hempel U, Wenzel KW, Bierhaus A, SChuh D, Dimmer V, Haroske G AND Muller M. 1998. Loss of caveolin expression in type I pneumocytes as an indicator of subcellular alterations during lung fibrogenesis. Histochem Cell Biol 109: 41-48.

LANChOU J, Corbel M And TANGUY M. 2003. Imbalance between matrix metalloproteinases (MMP-9 and MMP-2) and tissue inhibitors of metalloproteinases (TIMP-1 and TIMP-2) in acute respiratory distress syndrome patients. Crit Care Med 31: 536-542.

Li Y, Rahmanian M, Widstrom C, LePPERdinger G, FROST GI AND HELDIN P. 2000. Irradiation induced expression of hyaluronan (HA) synthase 2 and hyaluronidase 2 genes in rat lung tissue accompanies active turnover of HA and induction of types I and III collagen gene expression. Am J Resp Cell Mol Biol 23: 411-418.

Liu M, Tanswell AK and Post M. 1999. Mechanical force-induced signal transduction in lung cells. Am J Physiol Lung Cell Mol Physiol 277: L667-L683.

MCNEIL PL AND STEINHARDT RA. 1997. Loss, restoration, and maintenance of plasma membrane integrity. J Cell Biol 137: 1-4.

MERCER RR AND CRAPO JD. 1990. Spatial distribution of collagen and elastin fibres in the lungs. J Appl Physiol 69: 756-765.

MiserocChi G AND Negrini D. 1997. Pleural space: pressures and fluid dynamics. In: CRYSTAL RG, WEST JB, WeIBEL ER AND BARNES PJ (Eds), The Lung. $2^{\text {nd }}$ ed., Philadelphia: Lippincott-Raven, p. 1217-1225.

Miserocchi G, Negrini D And Gonano C. 1990. Direct measurements of interstitial pulmonary pressure in in situ lung with intact pleural space. J Appl Physiol 69: 2168 2174.

Miserocchi G, Negrini D, Del Fabbro M and VenTUROLI D. 1993. Pulmonary interstitial pressure in intact in situ lung: The transition to interstitial edema. J Appl Physiol 74: 1171-1177.

Miserocchi G, Negrini D, Passi A And De Luca G. 2001a. Development of lung edema: interstitial fluid dynamics and molecular structure. News Physiol Sci 16: 66-71.

Miserocchi G, Passi A, Negrini D, Del Fabbro M AND DE LuCA G. 2001b. Pulmonary interstitial pressure and tissue matrix structure in acute hypoxia. Am J Physiol Lung Cell Mol Physiol 280: L881-L887.

Montes GS. 1996. Structural biology of the fibres of the collagenous and elastic systems. Cell Biol Int 20: 15-27.
Negri EM, Montes GS, SAldiva PHN And CAPPeLOZZI VL. 2000. Architectural remodelling in acute and chronic interstitial lung disease: fibrosis or fibroelastosis Histopathology 37: 393-401.

NEGRINI D. 1995. Pulmonary microvascular pressure profile during development of hydrostatic edema. Microcirculation 2: 173-180.

Negrini D, Passi A, De Luca G and Miserocchi G. 1998. Proteoglycan involvement during development of lesional pulmonary edema. Am J Physiol 274: L203L211.

Negrini D, Passi A, De Luca G and Miserocchi G. 2003. Matrix proteoglycans in development of pulmonary edema. In: Garg HG, Roughley PJ AND Hales CA (Eds), Proteoglycans in lung disease, New York: Marcel Dekker, p. 143-168.

Negrini D, Tenstad O, Passi A And Wiig H. 2006. Differential degradation of matrix proteoglycans and edema development in rabbit lung. Am J Physiol Lung Cell Mol Physiol 290: L470-L477.

Nguyen NM, Bai Y, Mochitate K and Senior RM. 2002. Laminin alpha-chain expression and basement membrane formation by MLE-15 respiratory epithelial cells. Am J Physiol Lung Cell Mol Physiol 282: L1004L1011.

Noble PW And JiAng D. 2006. Matrix regulation of lung injury, inflammation, and repair: the role of innate immunity. Proc Am Thorac Soc 3: 401-404.

Palestini P, Calvi C, Conforti E, Daffara R, Botto L AND MiserocChi G. 2003. Compositional changes in lipid microdomains of air-blood barrier plasma membranes in pulmonary interstitial edema. J Appl Physiol 95: 1446-1452.

Passi A, Negrini D, Albertini R, De Luca G and MiserocChi G. 1998. Involvement of lung interstitial proteoglycans in development of hydraulic and elastase induced edema. Am J Physiol 275: L631-L635.

Passi A, Negrini D, Albertini R, Miserocchi G And DE LUCA G. 1999. The sensitivity of versican from rabbit lung to gelatinase A (MMP-2) and B (MMP-9) and its involvement in the development of hydraulic lung edema. FEBS Lett 456: 93-96.

RAZANi B, WoOdman SE AND LisAnTI MP. 2002. Caveolae: from cell biology to animal physiology. Pharmacol Rev 54: 431-467.

Roberts CR, Wight TN And Hascall VC. 1997. Proteoglycans. In: CRYSTAL RG, WeSt JB, WeIbEL ER 
AND BARnes PJ (Eds), The Lung. $2^{\text {nd }}$ ed., Philadelphia: Lippincott-Raven, p. 757-767.

Rocco PRM, Negri EM, Kurtz PM, VAsconcellos FP, Silva GH, CAPELOZZI VL, ROMERo PV AND ZIN WA. 2001. Lung tissue mechanics and extracellular matrix in acute lung injury. Am J Respir Crit Care Med 164: 1067-1071.

Rocco PRM, Souza AB, Faffe DS, Passaro CP, SANTOS FB, NEGRI EM, LIMA JGM, CONTADOR RS, CAPELOZZI VL AND ZIN WA. 2003. Effect of corticosteroid on lung parenchyma remodeling at an early phase of acute lung injury. Am J Respir Crit Care Med 168: $677-684$.

Ruoss SJ, Gold WM And Caughey GH. 1991. Mast cell exocytosis: evidence that granule proteoglycan processing is not coupled to degranulation. Biochem Biophys Res Commun 179: 140-146.

Santos FB, Nagato LKS, Boechem NM, Negri EM, Guimarães A, Capelozzi VL, FafFe DS, ZiN WA AND RoCCO PRM. 2006. Time course of lung parenchyma remodeling in pulmonary and extrapulmonary acute lung injury. J Appl Physiol 100: 98-106.

Souza Fernandes AB, Pelosi P and Rocco PRM. 2006. Bench-to-bedside review: The role of glycosaminoglycans in respiratory disease. Critical Care 10: 237.

TAMmi MI, DAY AJ AND Turley EA. 2002. Hyaluronan and homeostasis: a balancing act. J Biol Chem 277: 4581-4584.

TSCHUMPERLIN DJ, OSWARI J AND MARGULIES SS. 2000. Deformation- induced injury of alveolar epithelial cells. Am J Respir Crit Care Med 162: 357-362.
TSCHUMPERLIN DJ ET AL. 2004. Mechanotransduction through growth-factor shedding into the extracellular space. Nature 429: 83-86.

Tumova S, Woods A And Couchman JR. 2000. Heparan sulfate proteoglycans on the cell surface: versatile coordinators of cellular functions. Int $\mathrm{J}$ Biochem Cell Biol 32: 269-288.

Vlahakis NE and Hubmayr RD. 2005. Cellular Stress Failure in Ventilator-injured lungs. Am J Respir Crit Care Med 171: 1328-1342.

Vlahakis Ne, Schroeder MA, Pagano RE and HubMAYR RD. 2001. Deformation-induced lipid trafficking in alveolar epithelial cells. Am J Physiol Lung Cell Mol Physiol 280: L938-L946.

West JB And Mathieu-Costello O. 1999. Structure, strength, failure, and remodeling of the pulmonary bloodgas barrier. Annu Rev Physiol 61: 543-557.

WHITELOCK JM AND IOzzo RV. 2005. Heparan sulfate: a complex polymer charged with biological activity. Chem Rev 105: 2745-2764.

YURCHENKO PD AND SCHITTNY JC. 1990. Molecular architecture of basement membrane. FASEB J 4: 1577 1590.

Zhao J, Sime PJ, Bringas JR P, Gauldie J And WarBURTON D. 1999. Adenovirus-mediated decorin gene transfer prevents TGF-beta-induced inhibition of lung morphogenesis. Am J Physiol Lung Mol Cell Physiol 277: L412-L422.

ZWINKLER MP, IANCU D AND Michel RP. 1994. Effects of pulmonary fibrosis on the distribution of edema. Am J Respir Crit Care Med 149: 1276-1285. 